\title{
Template Approach to Large-Area Non-layered Ga- Group Two-Dimensional Crystals from Printed Skin of Liquid Gallium
}

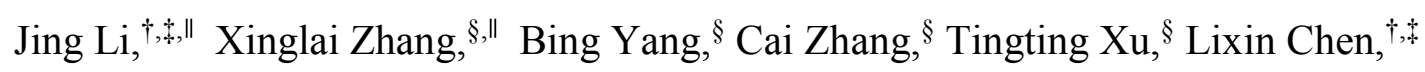

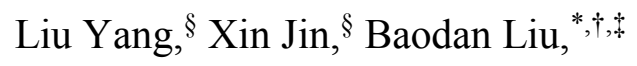

${ }^{\dagger}$ School of Material Science and Engineering, Northeastern University, No. 11

Wenhua Road, Shenyang 110819, China

\$Foshan Graduate School of Northeastern University, No. 2 Zhihui Road,

Foshan 528300, China

${ }^{\S}$ Shenyang National Laboratory for Materials Science (SYNL), Institute of Metal

Research (IMR), Chinese Academy of Sciences (CAS), No. 72 Wenhua Road,

Shenyang 110016, China

*Email: liubaodan@mail.neu.edu.cn. 
(a)

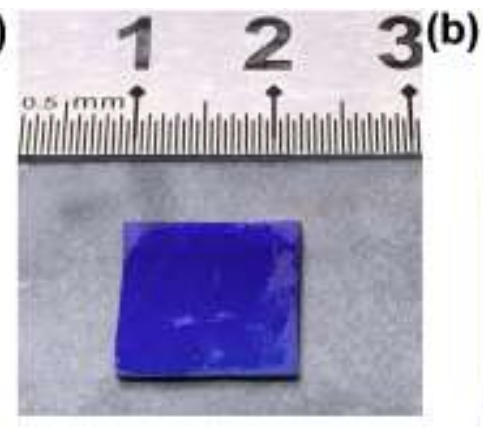

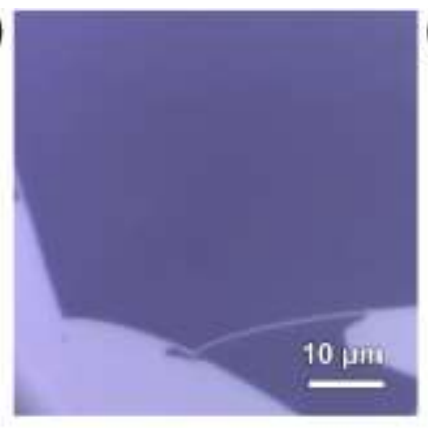

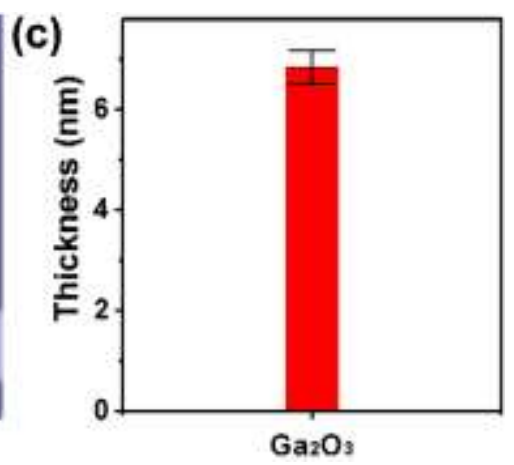

Figure S1. (a) Photograph and (b) photomicrograph of a centimeter-sized 2D $\mathrm{Ga}_{2} \mathrm{O}_{3}$ amorphous layer on the $\mathrm{SiO}_{2}$ substrate prepared by a PDMS printing method. (c) Statistic histogram of the thickness from AFM measurements of 5 samples (two points for every sample) of $2 \mathrm{D} \mathrm{Ga}_{2} \mathrm{O}_{3}$ layer.
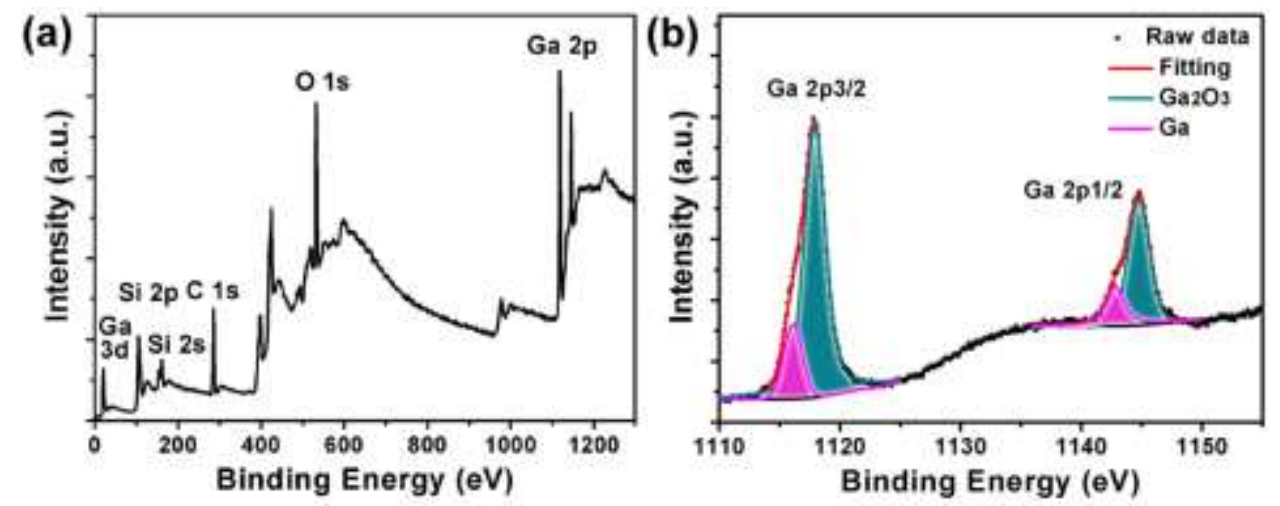

Figure S2. (a) XPS survey spectrum and (b) high resolution Ga 2p spectrum of a 2D $\mathrm{Ga}_{2} \mathrm{O}_{3}$ amorphous layer on the $\mathrm{SiO}_{2}$ substrate without heat treatment. 

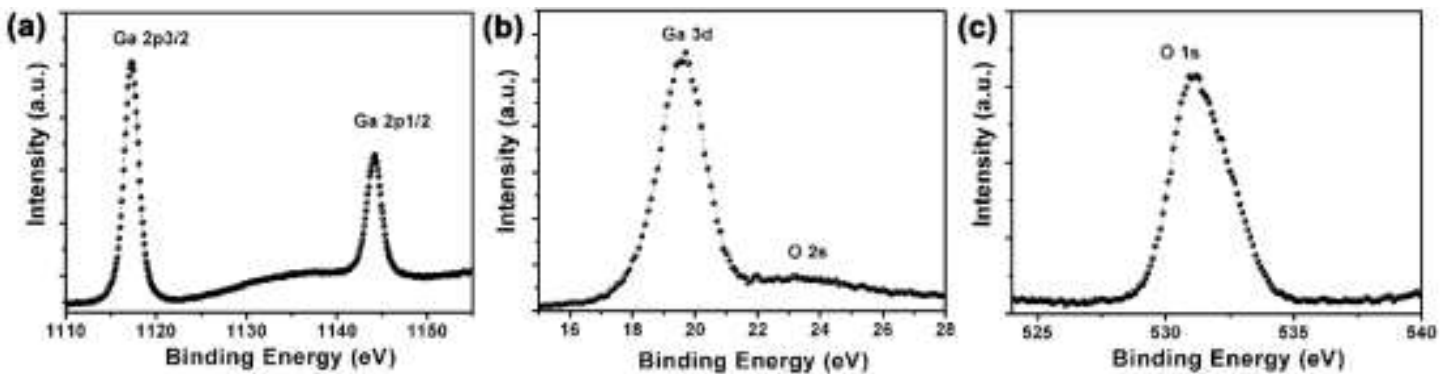

Figure S3. XPS spectra of (a) $\mathrm{Ga} 2 \mathrm{p}$, (b) $\mathrm{Ga} 3 \mathrm{~d}$ and (c) $\mathrm{O} 1 \mathrm{~s}$ for the $2 \mathrm{D} \mathrm{Ga}_{2} \mathrm{O}_{3}$ amorphous layer with a heat treatment at $500{ }^{\circ} \mathrm{C}$ for $30 \mathrm{~min}$.

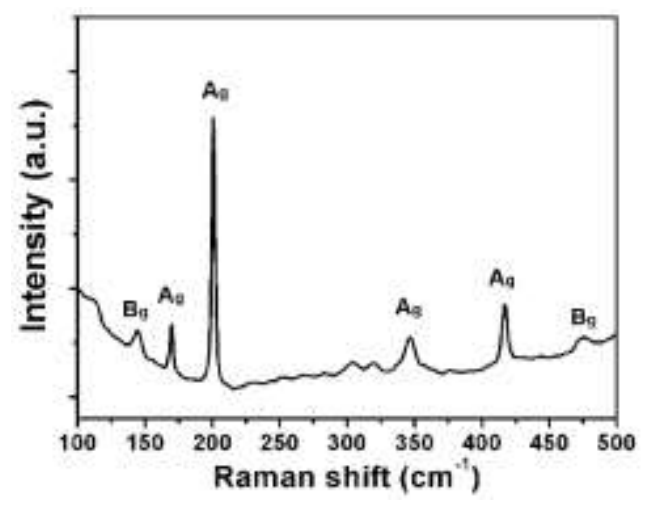

Figure S4. Raman spectrum of the $2 \mathrm{D} \mathrm{Ga}_{2} \mathrm{O}_{3}$ crystal obtained at $800{ }^{\circ} \mathrm{C}$ for $30 \mathrm{~min}$.
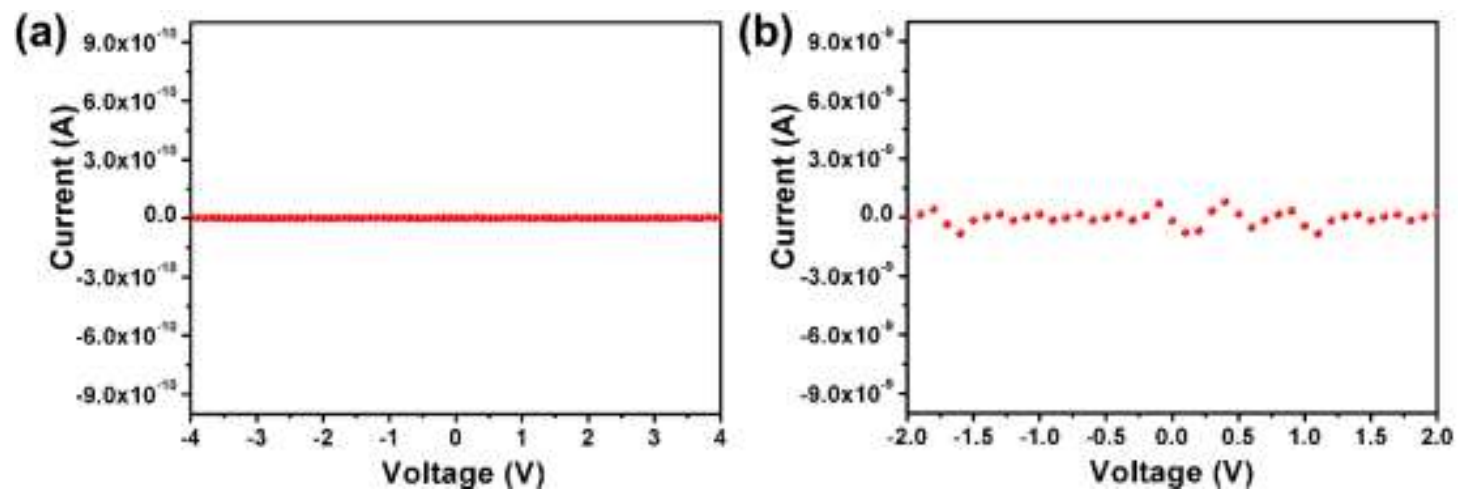

Figure S5. I-V characteristic curves of (a) the $2 \mathrm{D} \mathrm{Ga}_{2} \mathrm{O}_{3}$ amorphous layer obtained at $500{ }^{\circ} \mathrm{C}$ for $30 \mathrm{~min}$ and (b) the $2 \mathrm{D} \mathrm{Ga}_{2} \mathrm{O}_{3}$ polycrystal obtained at $800{ }^{\circ} \mathrm{C}$ for $30 \mathrm{~min}$. 


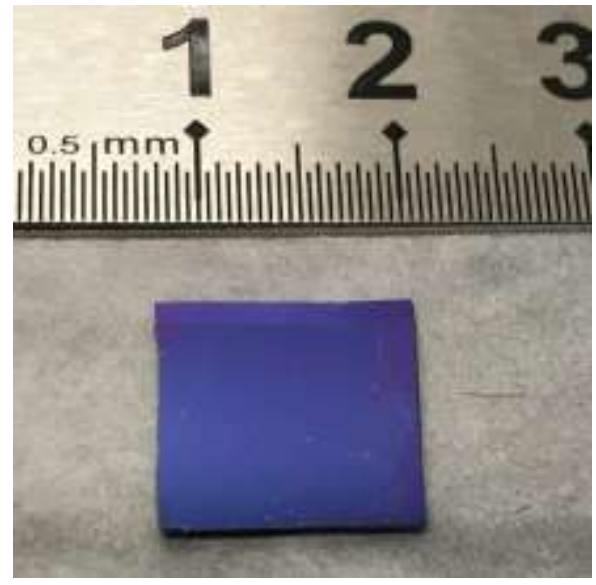

Figure S6. Optical image of a centimeter-sized 2D GaN crystal on the $\mathrm{SiO}_{2}$ substrate obtained from a nitridation treatment of the $2 \mathrm{D} \mathrm{Ga}_{2} \mathrm{O}_{3}$ amorphous layer at $800{ }^{\circ} \mathrm{C}$ for $10 \mathrm{~min}$.

(a)

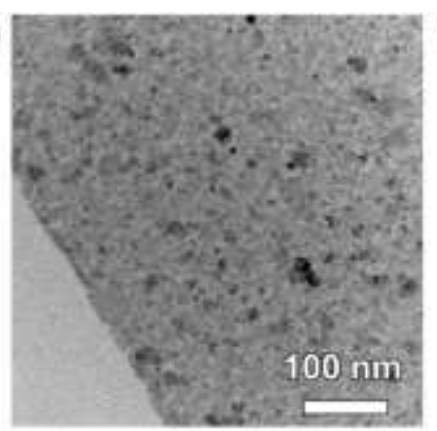

(d)

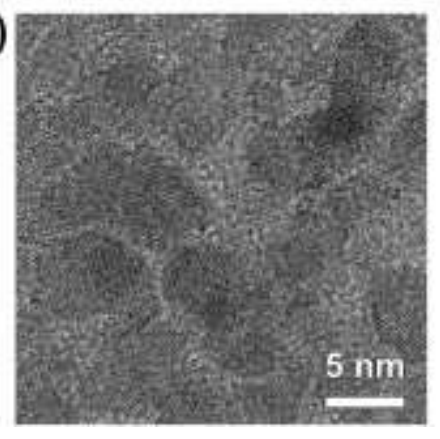

(b)

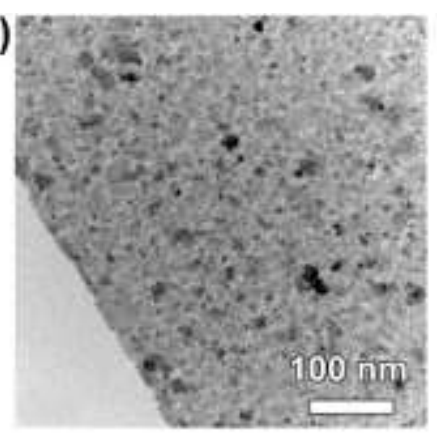

(e)

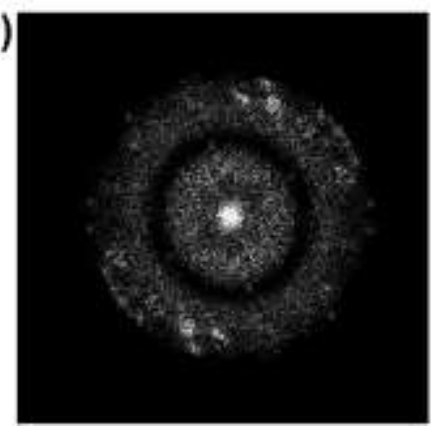

(c)

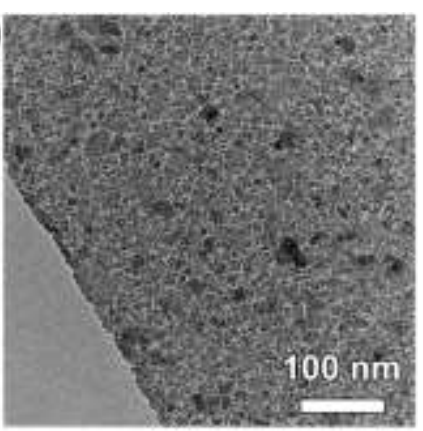

(f)

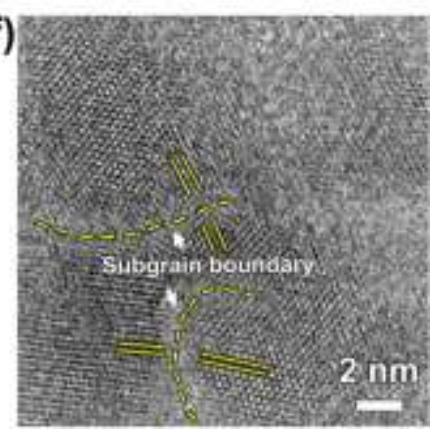

Figure S7. (a-c) TEM images at the different focus, (d-f) HRTEM images and (e) corresponding FFT of 2D GaN crystal. 
(a)

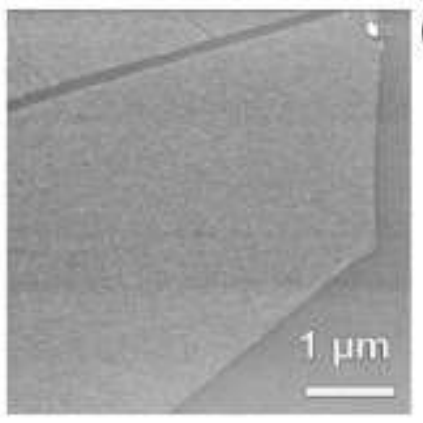

(b)

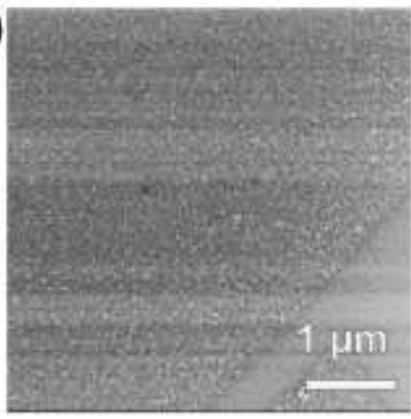

(d)

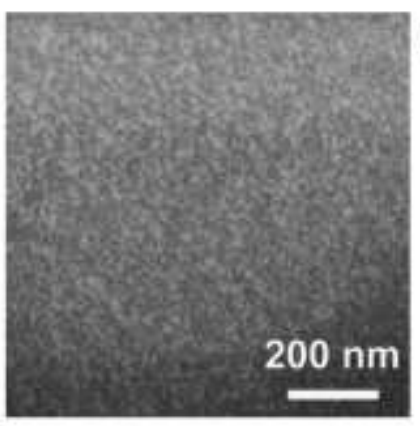

(e)

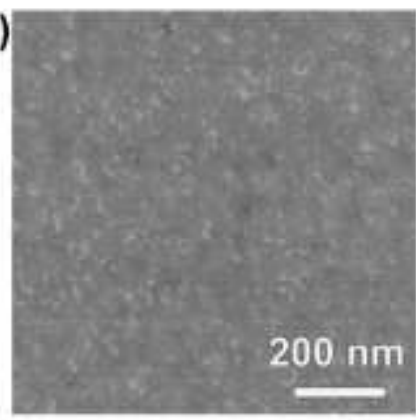

(c)

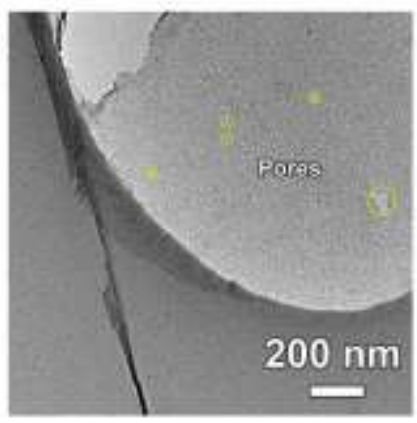

(f)

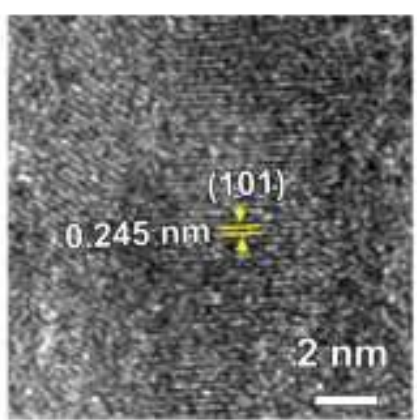

Figure S8. SEM images of the $2 \mathrm{D}$ GaN crystal prepared at $800^{\circ} \mathrm{C}$ for different reaction times: (a, d) 15min and (b, e) 20 min. (c) TEM and (f) HRTEM images of the $2 \mathrm{D} \mathrm{GaN}$ crystal prepared at $800^{\circ} \mathrm{C}$ for $20 \mathrm{~min}$.

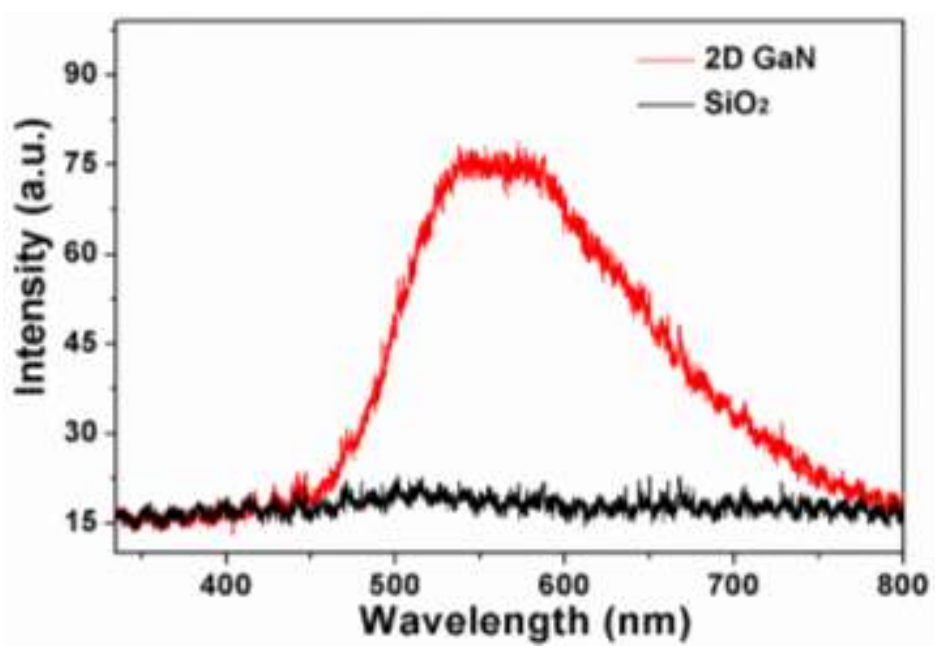

Figure S9. Photoluminescence spectrum of 2D GaN crystal. 

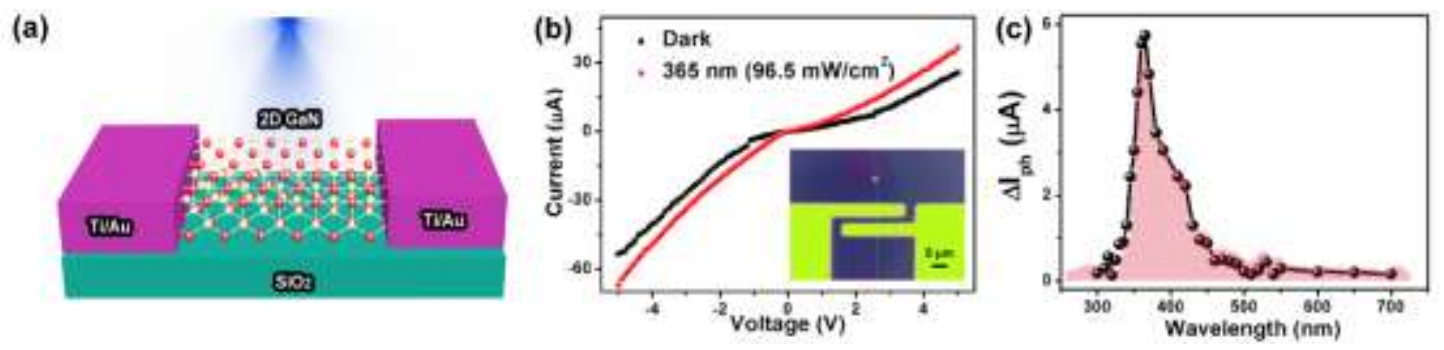

Figure S10. (a) 3D schematic diagram of 2D GaN optoelectronic device. (b) I-V characteristic curves of 2D GaN device under dark and strong light (365 nm LED) (inset is the photograph of device). (c) Photocurrent curves of the device as a dependence of different wavelengths ranging from 300-700 nm.

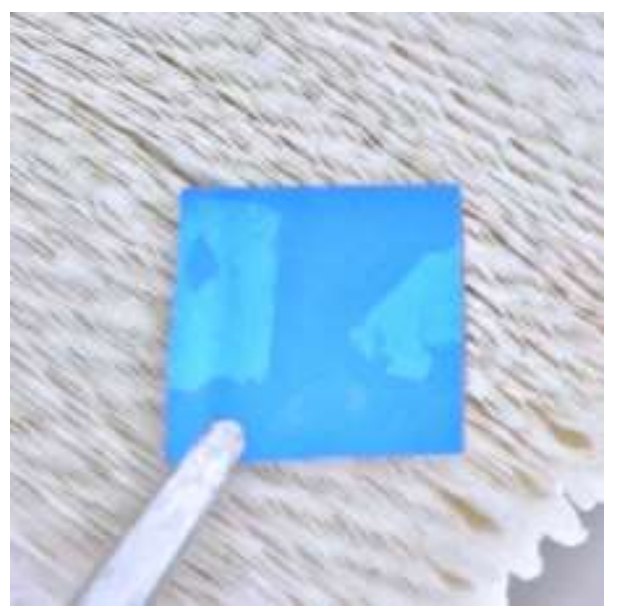

Figure S11. Optical image of the 2D GaP crystal obtained from a phosphorization treatment of the $2 \mathrm{D} \mathrm{Ga}_{2} \mathrm{O}_{3}$ amorphous layer at $600{ }^{\circ} \mathrm{C}$ for $10 \mathrm{~min}$. 

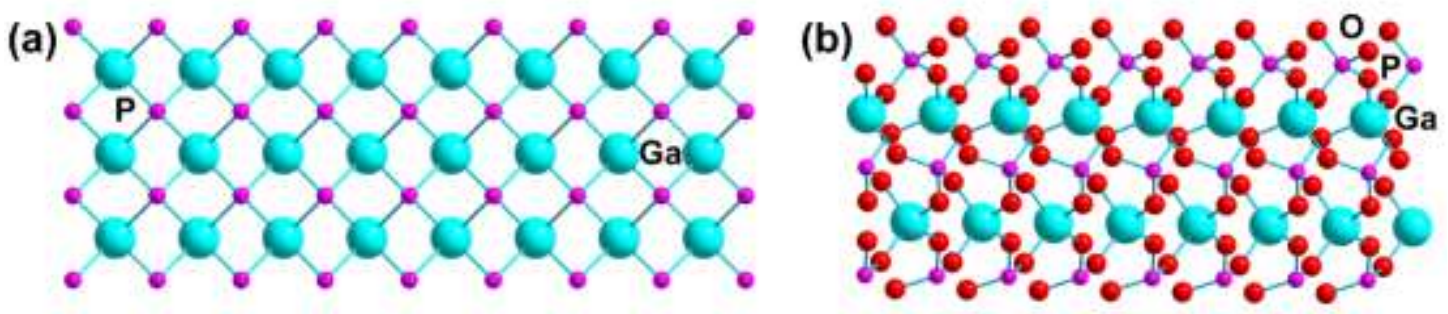

Figure S12. Schematic diagram of atomic model for (a) $\mathrm{GaP}$ and (b) $\mathrm{GaPO}_{4}$ crystals.
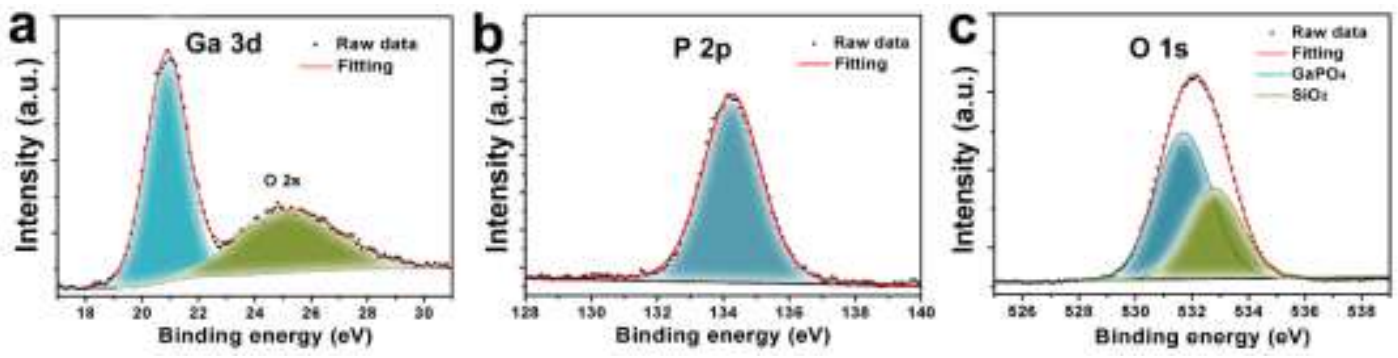

Figure S13. High resolution XPS spectra of (a) Ga 3d, (b) P 2p and (c) O 1s for 2D GaP crystal. 


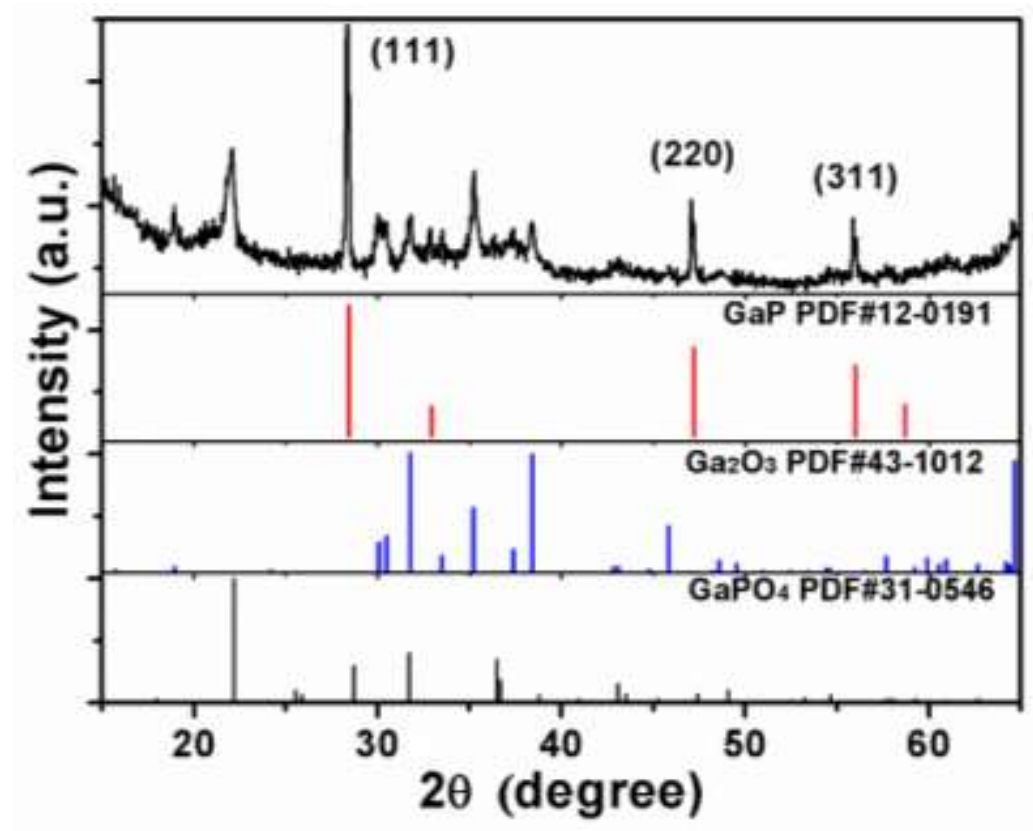

Figure S14. XRD pattern of the thick $\mathrm{GaP}$ film prepared by a phosphorization treatment of thick $\mathrm{Ga}_{2} \mathrm{O}_{3}$ film at $600{ }^{\circ} \mathrm{C}$ for $30 \mathrm{~min}$. The phase of $\beta-\mathrm{Ga}_{2} \mathrm{O}_{3}$ are mainly due to the incomplete phosphorization treatment. 


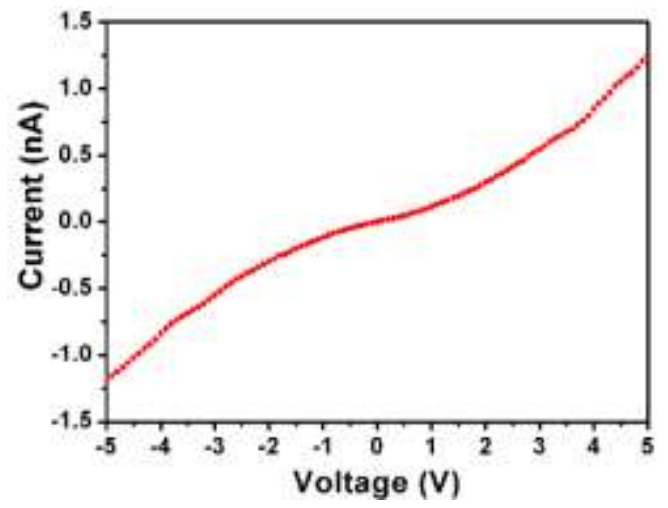

Figure S15. I-V curves of the $2 \mathrm{D}$ GaP crystal obtained from a phosphorization treatment of the $2 \mathrm{D} \mathrm{Ga}_{2} \mathrm{O}_{3}$ amorphous layer at $600{ }^{\circ} \mathrm{C}$ for $30 \mathrm{~min}$.

(a)

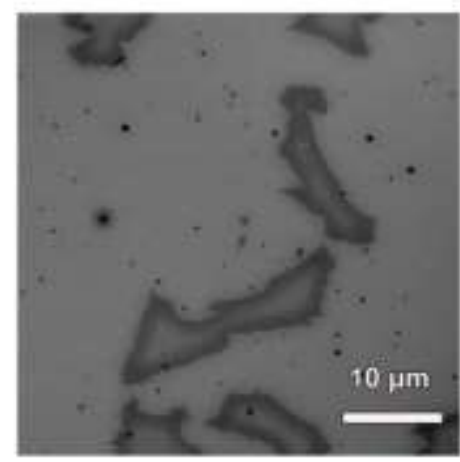

(c)

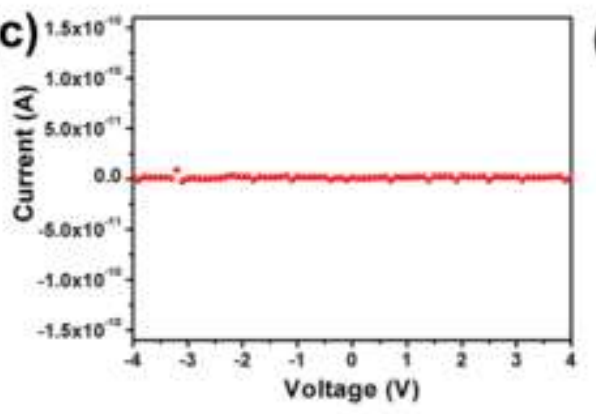

(b)

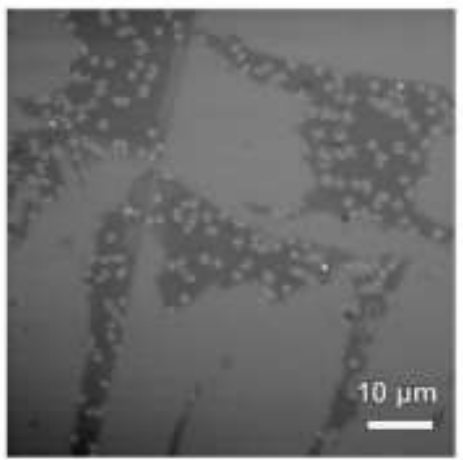

(d)

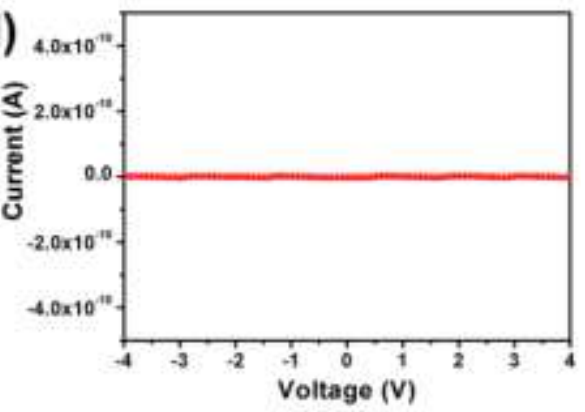

Figure S16. (a-b) SEM images and (c-d) I-V characteristic curves of 2D GaP crystal obtained from a phosphorization treatment of the $2 \mathrm{D} \mathrm{Ga}_{2} \mathrm{O}_{3}$ amorphous layer at $700{ }^{\circ} \mathrm{C}$ and $800{ }^{\circ} \mathrm{C}$ for $10 \mathrm{~min}$. 
(a)

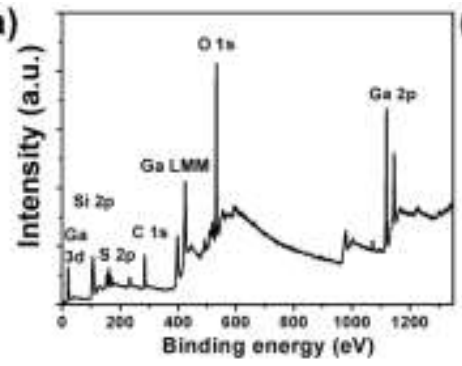

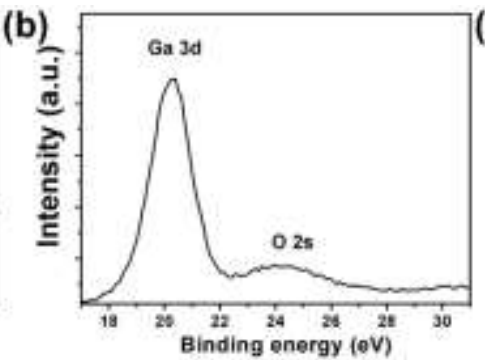

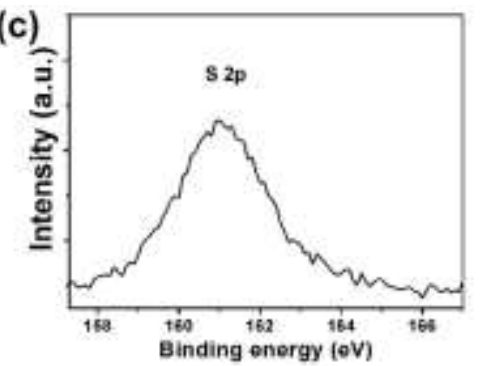

Figure S17. (a) XPS survey spectrum and (b-c) high resolution Ga 3d and S 2p spectra of 2D GaS crystal.
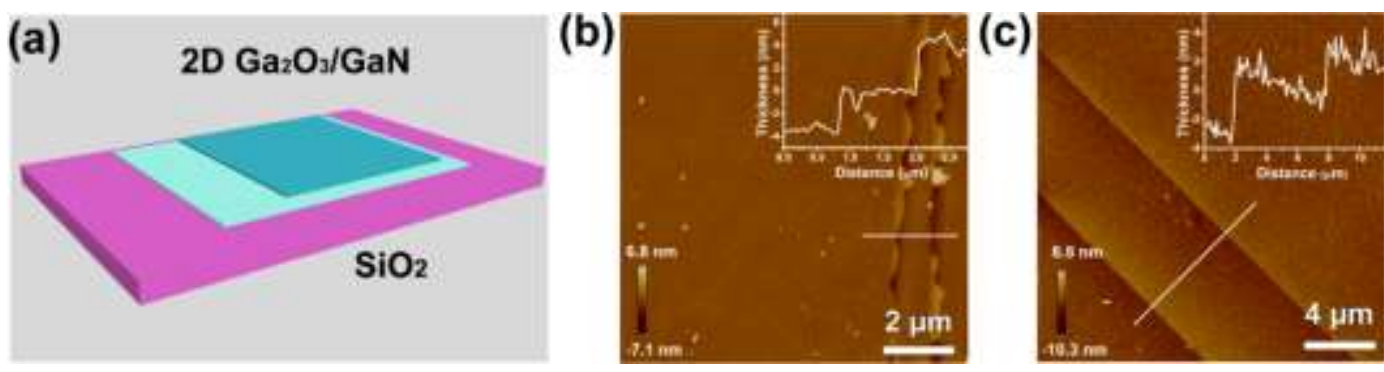

Figure S18. (a) Schematic diagram of the stacking of 2D Ga-group crystals. AFM images of (b) bilayer 2D Ga $2 \mathrm{O}_{3}$ crystal and (c) bilayer 2D GaN crystal via the PDMS printing method and subsequent heat treatments. 


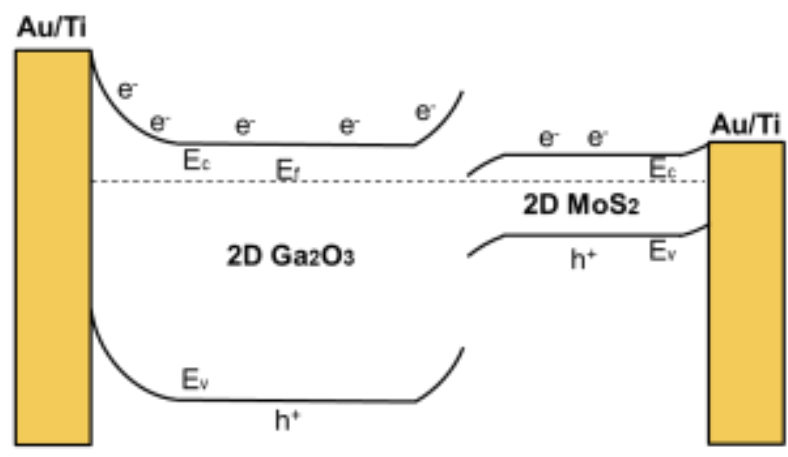

Figure S19. Schematic of the energy band diagrams of contact barrier among metal electrodes, $\mathrm{Ga}_{2} \mathrm{O}_{3}$ and $\mathrm{MoS}_{2}$.

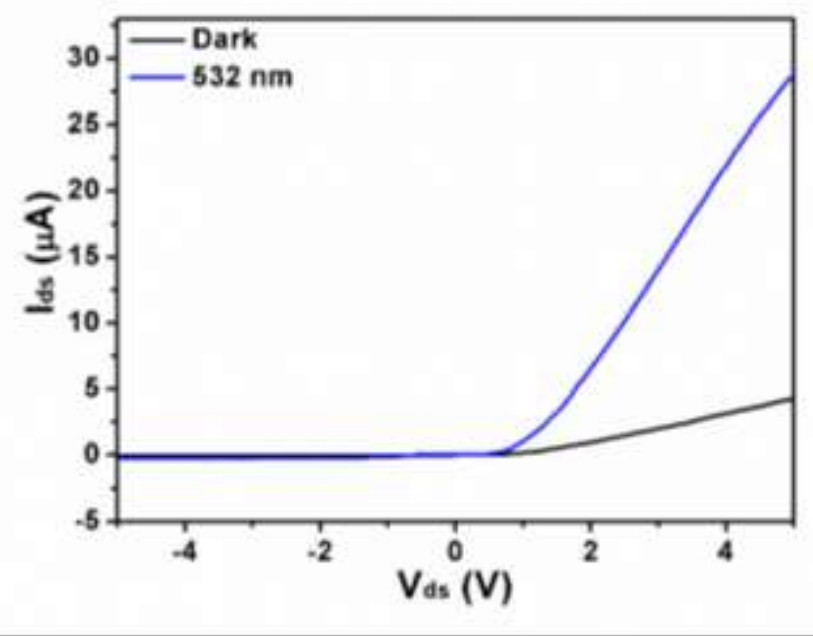

Figure S20. I-V curves of the obtained stacking $2 \mathrm{D} \mathrm{Ga}_{2} \mathrm{O}_{3} / \mathrm{MoS}_{2}$ device under the light irradiation of $532 \mathrm{~nm}$ (light intensity: $95 \mathrm{~mW} / \mathrm{cm}^{2}$ ) and the dark condition. 